\title{
LEVANTAMENTO FLORÍSTICO E ANÁLISE FITOSSOCIOLÓGICA DE UM REMANESCENTE DE FLORESTA OMBRÓFILA MISTA LOCALIZADO NO MUNICÍPIO DE PINHAIS, PARANÁ-BRASIL
}

\author{
Celso Darci Seger*, Fernando Luis Dlugosz*, Gilberto Kurasz*, Diego Tyszka Martinez*, \\ Elisangela Ronconi*, Luiz Antônio Nunes de Melo*, Sérgio M. de Bittencourt*, Martha Andréa Brand**, \\ Irene Carniatto**, Franklin Galvão***, Carlos Vellozo Roderjan*** \\ * Mestrandos em Eng. Florestal, UFPR - celsoseger@aol.com \\ ** Doutorandos em Eng. Florestal, UFPR - martha@uniplac.com.br \\ *** Eng. Florestal, Dr., Depto. de Ciências Florestais da UFPR - fgalvao@floresta.ufpr.br - roderjan@floresta.ufpr.br
}

Recebido para publicação: 16/12/2004 - Aceito para publicação: 31/08/2005

\begin{abstract}
Resumo
Levantamento florístico e análise fitossociológica de um remanescente de Floresta Ombrófila Mista localizado no municipio de Pinhais, Paraná-Brasil. Com o propósito de reunir informações florísticas e fitossociológicas de um capão de Floresta com Araucária em uma área de preservação do Condomínio Residencial Alphaville Graciosa, foi executado o presente estudo. A metodologia aplicada para a obtenção dos dados fundamentou-se na alocação de parcelas, onde foram amostrados todos os indivíduos com PAP (perímetro a altura do peito) maior que 15 centímetros. Foram estabelecidas aleatoriamente 15 parcelas de $10 \times 10$ metros em duas unidades geopedológicas distintas, sendo 10 em Cambissolo Húmico e 5 em Gleissolo Háplico. Na somatória das duas unidades registraram-se 307 indivíduos, sendo 274 vivos e 33 mortos. Dentre os vivos, identificaram-se 44 espécies pertencentes a 31 gêneros vinculados a 21 famílias. Para o Cambissolo Húmico registraramse 35 espécies, enquanto para o Gleissolo Háplico 22, sendo 14 espécies comuns, determinando uma similaridade florística muito baixa entre os compartimentos. As espécies de maior valor de importância (VI) encontradas no Cambissolo Húmico foram Araucaria angustifolia (50,94), Podocarpus lambertii $(46,42)$ e Myrcia multiflora $(27,76)$, enquanto que para o Gleissolo Háplico, Myrsine umbellata $(71,51)$ e Sebastiania commersoniana $(32,52)$.

Palavras-chave: Floresta com Araucária; fitossociologia; unidades pedológicas; área de preservação.
\end{abstract}

\begin{abstract}
Floristic composition and phytosociological analysis of a Mixed Araucaria Forest remainder in Pinhais county, Paraná state - Brazil. This research intended to present the Floristic Composition and Phytosociological Analysis of an Araucaria Forest remainder. At the studied area, two different pedologycal units were analyzed; in each area 15 square samples (10X10) were randomly distributed. Within both units it was numbered 307 trees (pbh $\geq 15 \mathrm{~cm}$ ), even 33 dead ones. 44 species were detected among the 274 alive individuals, belonging to 31 genus and 21 families. The most important species due to value importance (VI) were: Myrsine umbellata (71,51) Araucaria angustifolia $(50,94)$, Podocarpus lambertii $(46,42)$, Sebastiania commersoniana $(32,52)$ and Myrcia multiflora $(27,76)$.
\end{abstract}

Keywords: Araucaria Forest; phytossociology; pedologycal units; preservation area.

\section{INTRODUÇÃO}

De acordo com descrições feitas por Maack (1981), grande parte da Região Metropolitana de Curitiba, incluindo o município de Pinhais, era primitivamente composta por campos limpos ou estepes (campos de Curitiba), formação vegetacional típica do estado do Paraná num período geológico distante, quando o clima predominante era o semi-árido.

Manchas florestais compostas de Floresta Ombrófila Mista (Floresta com Araucária), popularmente designadas de capões, espalhavam-se por entre os campos, geralmente se estabelecendo no entorno de nascentes, ou então às margens de rios, constituindo as florestas de galeria. Muito embora a 
intensa ação antrópica registrada em anos passados tenha descaracterizado profundamente a paisagem natural da região, parte dessa vegetação arbórea foi mantida, constituindo-se em locais ideais para estudos.

A Floresta com Araucária tem como característica marcante a coexistência de floras de origens distintas, uma temperada (austro-brasileira), bastante antiga, oriunda de um clima pretérito mais frio, e outra tropical (afro-brasileira), associada à maior temperatura e umidade das condições climáticas hodiernas (IBGE, 1992). A característica mais marcante dessa formação é a presença de Araucaria angustifolia, conhecida popularmente como pinheiro-do-paraná, e também elementos dos gêneros Drymis e Podocarpus, ocorrendo em associações diversificadas com espécies das famílias Lauraceae, Myrtaceae, Aquifoliaceae, Anacardiaceae, Flacourtiaceae, Euphorbiaceae e Sapindaceae, entre outras. Esse bioma tem sido considerado um dos mais notáveis em termos de valor ecológico, por abrigar espécies típicas e atributos biológicos únicos em todo o planeta. Igualmente, por apresentar uma exuberância de recursos madeiráveis e não-madeiráveis, teve grande influência no desenvolvimento do Sul do Brasil a partir do início do século passado, gerando progresso e riqueza nessa região (AMBIENTE BRASIL, 2004).

$\mathrm{O}$ intenso desmatamento reduziu a extensa área que era coberta por essa formação fitoecológica a fragmentos esparsos, os quais geralmente encontram-se alterados e, por conseqüência, empobrecidos em sua composição florística original. Apesar disso, devem ser considerados como valiosos recursos naturais renováveis, passíveis de utilização tanto pelas presentes como pelas futuras gerações (FUPEF-CNPQ, 2001).

Em vista desses fatos, a preservação das poucas áreas de Floresta Ombrófila Mista que ainda restam deve ser encorajada, não só por parte do poder público, mas também pela iniciativa privada. $\mathrm{O}$ presente estudo teve como objetivos descrever a composição florística e a estrutura fitossociológica de um remanescente de Floresta Ombrófila Mista, situado dentro dos limites do Condomínio Residencial Alphaville Graciosa, perímetro urbano do município de Pinhais (PR), assim como analisar a similaridade florística entre as distintas unidades pedológicas presentes na área e entre o presente estudo e demais levantamentos já publicados.

\section{MATERIAL E MÉTODOS}

\section{Localização e caracterização da área de estudo}

A área de estudo compõe-se de um fragmento (capão) de Floresta Ombrófila Mista com tamanho de 11,62 hectares (RESITEC, 1999), apresentando compartimentos fisionômicos distintos em consonância com os diferentes tipos de solos presentes, denominados por IBGE (1992) de Floresta Ombrófila Mista Montana e Floresta Ombrófila Mista Aluvial. Mesmo que não tenha passado imune às alterações provocadas pela ação humana, apresenta-se ainda relativamente conservada.

Localiza-se no interior do Condomínio Residencial Alphaville Graciosa (49 $07^{\prime} 50^{\prime \prime} \mathrm{W}$ e $25^{\circ} 24^{\prime}$ 25" S), nas proximidades dos contrafortes da Serra do Mar, município de Pinhais, divisa leste com o município de Curitiba. A altitude é de aproximadamente 900 m.s.n.m., com relevo suavemente ondulado e rede de drenagem da vertente oeste da Serra do Mar, compondo a bacia hidrográfica do Alto Rio Iguaçu (RESITEC, 1999).

O clima regional é, de acordo com a classificação de Köppen, do tipo Cfb - temperado, onde os verões são frescos, com média de temperatura inferior a $22{ }^{\circ} \mathrm{C}$, e os invernos severos, apresentando no mês mais frio temperatura média inferior a $18^{\circ} \mathrm{C}$, com ocorrência de geadas freqüentes (FUNPAR, 2002). Embora não tenha influência direta do oceano, possui chuvas bem distribuídas ao longo do ano, o que determina uma umidade relativa do ar média em torno de $85 \%$, e a precipitação em torno de $1.400 \mathrm{~mm}$ anuais (FUNPAR, 2002).

\section{Compartimentação pedológica}

De acordo com Leite (1994), em regiões onde a colonização da vegetação ocorre de forma espontânea (natural), a pedologia assume caráter diferenciado para a expansão e desenvolvimento de diferentes espécies. Com base nessa citação, o primeiro passo para a coleta de dados foi um levantamento dos diferentes tipos de solo encontrados na área de estudo. A área em questão encontra-se na bacia de Curitiba, situada em uma calha estrutural alongada de pequena profundidade em direção NE-SW, caracterizada por uma ampla diversidade geológica. Para a área estudada, dois tipos de solos foram 
encontrados. Nas porções mais elevadas e de melhor drenagem, o solo classificado como Cambissolo Húmico distrófico típico e léptico, fase argilosa, relevo ondulado, substrato argilito. Nas baixadas, junto a pequenos cursos de águas oriundos de nascentes do interior do capão, Gleissolo Háplico distrófico típico, A moderado, textura argilosa, relevo plano e suave ondulado.

Conforme a classificação proposta pela EMBRAPA (1999), as formações pedológicas compostas de Cambissolo Húmico compreendem solos minerais não-hidromórficos, de pequeno grau de evolução pedogenética, com horizonte B incipiente, subjacente a qualquer tipo de horizonte superficial. A espessura geralmente é inferior a $50 \mathrm{~cm}$, apresentando elevada fragilidade devido a sua suscetibilidade à erosão. Como conseqüência da heterogeneidade do material de origem, associado às formas de relevo e condições climáticas, as características desse solo variam fortemente entre diferentes locais. No caso da região onde se encontra a área de estudo, a ocorrência de horizontes superficiais mais ricos em matéria orgânica, proeminente e húmico, está diretamente relacionada à presença da Serra do Mar, a qual proporciona maior grau de nebulosidade e, conseqüentemente, menores taxas de oxidação da matéria orgânica (Gustavo Ribas Curcio, comunicação pessoal). Originalmente, os Cambissolos eram revestidos tanto por cobertura vegetal arbórea como herbácea (campo mesófilo). Já o Gleissolo Háplico é constituído por material mineral com horizonte glei imediatamente abaixo do horizonte A. É um solo hidromórfico que em condições naturais é mal drenado (EMBRAPA, 1999), além de fortemente ácido, com baixa saturação por bases e elevados teores de alumínio trocável. Os constantes aportes de sedimentos oriundos de processos de aluvionamento dificultam a sua pigmentação pela matéria orgânica. Em ambientes tipicamente anaeróbicos, a altura e o tempo de permanência do lençol freático influenciam diretamente no estabelecimento de florestas hidrófilas e higrófilas, dominando assim a paisagem sobre esse solo.

\section{Procedimento metodológico para o estudo florístico}

Para o levantamento florístico e análise fitossociológica, utilizou-se o método de Parcelas Múltiplas (Mueller-Dumbois e Ellenberg, 1974), com o estabelecimento de 15 parcelas de 10x10 metros, totalizando $1.500 \mathrm{~m}^{2}$ (0,15 ha), sendo 10 delas em Cambissolo Húmico e 5 em Gleissolo Háplico. Todos os indivíduos arbóreos e arbustivos presentes com PAP (perímetro à altura do peito) igual ou superior a 15 centímetros foram amostrados, coletando-se, sempre que necessário, material vegetativo para identificação das espécies e posterior herborização, conforme as recomendações de Fidalgo e Bononi (1984). Todo o material coletado e identificado foi depositado no Herbário Escola de Florestas de Curitiba (EFC), do Departamento de Ciências Florestais da UFPR.

A identificação taxonômica foi realizada em campo, com base nos aspectos dendrológicos das espécies, e em laboratório, por meio de literatura especializada e envio de material para especialista.

\section{Análise dos dados}

Para a compilação dos dados e representação gráfica dos resultados, empregou-se o software Microsoft Excel 97, enquanto que, para o processamento dos dados para o cálculo de descritores (Densidade, Dominância, Freqüência e Valor de Importância) usou-se o pacote de programas FITOPAC 1.0 (Shepherd, 1988).

Para a estimativa da diversidade específica, empregou-se o índice de Shannon (Magurran, 1989), expresso pela formula $\mathrm{H}^{\prime}=-\sum$ pi $\ln \mathrm{pi} \rightarrow \mathrm{pi}=$ ni/N, onde pi = proporção de indivíduos da i-ésima espécie; ni = número de indivíduos amostrados para a espécie $\mathrm{i}$; e $\mathrm{N}=$ número total de indivíduos amostrados.

Devido à diferenciação dos compartimentos, procedeu-se uma análise de similaridade florística entre ambas, utilizando-se o Índice de Similaridade de Jaccard (Mueller-Dumbois e Ellenberg, 1974), cuja fórmula é: $\mathrm{Isj}=\mathrm{c} /(\mathrm{a}+\mathrm{b}+\mathrm{c}) \times 100$, onde: $\mathrm{c}=$ número de espécies comuns, $\mathrm{a}=$ número de espécies exclusivas da área $\mathrm{A} \mathrm{e} \mathrm{b}=$ número de espécies exclusivas da área $\mathrm{B}$. Esse índice também foi utilizado para a análise da similaridade florística entre o presente estudo e outros levantamentos fitossociológicos realizados em Floresta Ombrófila Mista disponíveis na literatura, caso de Nascimento et al. (2001), Negrelle e Silva (1992), Rondon Neto et al. (2002) e Sanquetta et al. (2002).

Quanto à análise de agregação de indivíduos da mesma espécie, fez-se uso do índice de McGuinnes (IGA) ou índice de agregação, através da fórmula IGA $=\mathrm{D} / \mathrm{d}$, onde: $\mathrm{D}=$ número total de indivíduos da espécie/número total de parcelas alocadas, enquanto que $d=-\ln (1-\underline{F A} / 100)$. No caso de IGA $<1,0$, a distribuição é uniforme; em IGA =1,0, a distribuição é aleatória; em IGA $>1,0$ e $<2,0$ há uma tendência ao agrupamento; e em IGA > 2,0 ocorre agregação. 


\section{RESULTADOS E DISCUSSÃO}

\section{Composição florística}

Na Tabela 1 pode ser observada a relação de espécies amostradas no remanescente da Floresta Ombrófila Mista em estudo e o compartimento em que ocorrem. No total de parcelas alocadas, $10 \mathrm{em}$ Cambissolo Húmico e 5 em Gleissolo Háplico, amostraram-se 307 indivíduos arbóreos e arborescentes, dos quais 274 vivos e 33 mortos em pé. Dentre os vivos, catalogaram-se 44 espécies vinculadas a 21 famílias, das quais, 42 identificadas em nível de espécie e duas em nível de gênero.

Tabela 1. Lista de espécies e ocorrência nas unidades pedológicas analisadas.

Table 1. Species list and distribution at the two pedologycal units analysed.

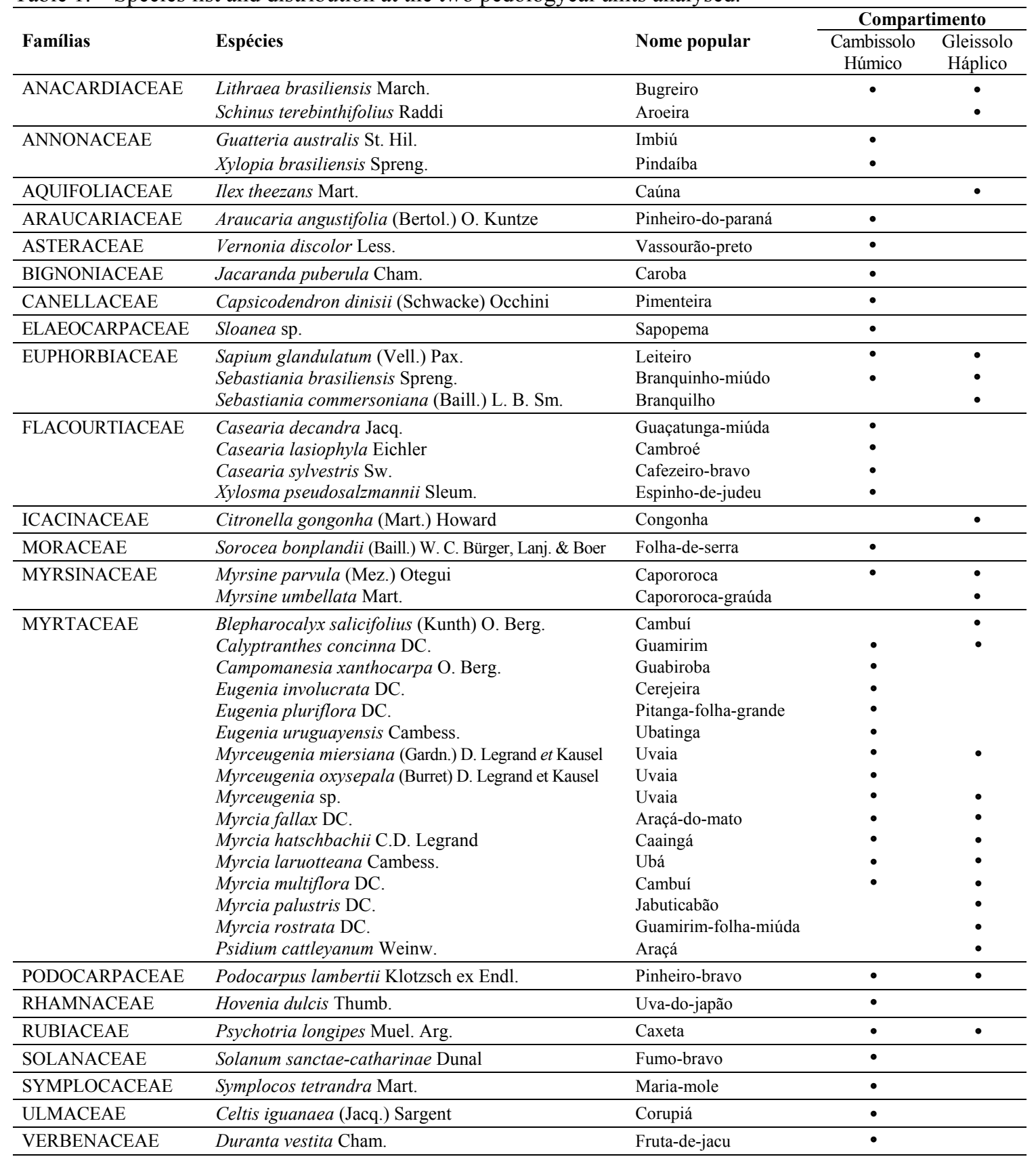


Myrtaceae, com 16 espécies vinculadas a 7 gêneros, Flacourtiaceae, com 4 espécies distribuídas em 2 gêneros, e Euphorbiaceae, representada por 3 espécies pertencentes a 2 gêneros, foram as famílias mais representativas. Juntas, contribuíram com 23 espécies, ou seja, mais da metade $(52,27 \%)$ dos registros. Para as demais famílias, 3 apresentaram 2 espécies, enquanto que as outras 15, apenas uma.

Esses resultados, ao serem comparados com outros trabalhos realizados em áreas de Floresta Ombrófila Mista, demonstram que a presença de uma maior quantidade de espécies das famílias Myrtaceae e Flacourtiaceae segue praticamente um padrão florístico para essa formação florestal. Porém, a ausência de determinadas famílias, que a princípio são bastante comuns, como Fabaceae, Sapindaceae e principalmente Lauraceae, foi considerada como um fato atípico. Certas lauráceas, como as pertencentes aos gêneros Ocotea, Nectandra e Cinnamomum, mesmo em litologias diferenciadas, aparecem com grande freqüência, inclusive em remanescentes bastante alterados, como constatado por Negrelle e Silva (1992) em um remanescente no município de Caçador (SC), Nascimento et al. (2001) em uma amostra de Floresta Ombrófila Mista em Nova Prata (RS), Rondon Neto et al. (2002) num capão encravado na cidade de Curitiba (PR) e Sanqueta et al. (2002) em um fragmento no centro-sul do Paraná. A nãoobservação dessas famílias provavelmente está ligada à ocorrência de uma intensa exploração seletiva, especialmente em relação às espécies da família laurácea, o que fez com que atualmente sejam raras na área, a ponto de não serem amostradas. Outra possibilidade é que, no atual estágio de sucessão do remanescente estudado, as espécies dessa família se encontrem com um porte abaixo do perímetro de inclusão, não sendo, assim, contempladas nas amostragens feitas.

Interessante destacar que no Estudo de Impacto Ambiental (EIA) feito pela RESITEC (1999) para a implantação do Condomínio Residencial Alphaville Graciosa, diferentes espécies de lauráceas foram listadas, dentre as quais, Ocotea porosa, O. puberula, O. odorifera e Nectandra sp. Para o estudo em questão, uma área bem maior de amostragem foi definida, abrangendo, além do capão aqui analisado, também outros presentes na área do condomínio.

Do total de espécies amostradas, 35 foram observadas em Cambissolo Húmico e 22 em Gleissolo Háplico, com 13 comuns aos dois compartimentos. Com base nessas informações e utilizando o índice de Jaccard, obteve-se uma similaridade florística de apenas 29,54\% entre esses dois compartimentos. Esse valor está muito próximo do limite abaixo do qual se considera que não há similaridade entre diferentes unidades analisadas, que é de $25 \%$. De certa forma, esse resultado já era esperado, por conta de serem ambientes geopedológicos distintivos, sendo o Gleissolo Háplico muito restritivo pelo excesso de água.

Utilizando-se igualmente o índice de Jaccard para uma comparação florística entre os compartimentos estudados e outros trabalhos realizados também em áreas de Floresta Ombrófila Mista (Negrelle e Silva, 1992; Nascimento et al., 2001; Rondon Neto et al., 2002 e Sanquetta et al., 2002), obtiveram-se os valores apresentados na Tabela 2. Por meio desses valores, constatou-se que, para o Cambissolo Húmico, em somente uma situação (comparação entre a florística de Cambissolo Húmico e o trabalho de Rondon Neto et al., 2002) existiu uma similaridade, quando o índice obtido foi de 33,3\%. Para a unidade Gleissolo Háplico, em nenhum dos quatro trabalhos comparados houve similaridade.

Tabela 2. Resultados da análise da similaridade florística entre as duas unidades geopedológicas da área de estudo com outras publicações.

Table 2. Results of similar floristic analyses between the two geo-pedologycal units of studied area and others publications.

\begin{tabular}{|c|c|c|c|c|}
\hline \multirow{2}{*}{ Unidade Geopedológica } & \multicolumn{4}{|c|}{ Publicações } \\
\hline & 1 & 2 & 3 & 4 \\
\hline Cambissolo Húmico & 11,3 & 13,9 & 33,3 & 18,5 \\
\hline Gleissolo Háplico & 14,9 & 10,5 & 20,0 & 7,7 \\
\hline
\end{tabular}

Onde: 1. Nascimento et al. (2001); 2. Negrelle e Silva (1992); 3. Rondon Neto et al. (2002); 4. Sanquetta et al. (2002)

De acordo com a tabela, os maiores valores, tanto para o Cambissolo Húmico como para o Gleissolo Háplico, foram obtidos com o trabalho de Rondon Neto et al. (2002), cuja localização geográfica e unidade geopedológica da área analisada são as mais concordantes com a do presente estudo. Outro aspecto, é que Cambissolo Húmico, com exceção de um caso, apresentou os maiores valores, demonstrando que mesmo que em três situações os índices obtidos não tenham definido uma 
similaridade, a flora desse compartimento apresenta uma aproximação maior com as dos trabalhos comparados, ao contrário do que acontece para o Gleissolo Háplico. Muito provável que os resultados da tabela estejam diretamente ligados, de um lado, à falta de homogeneidade geopedológica dos estudos que serviram de comparação, com exceção do de Rondon Neto et al. (2002), e, de outro, à não-presença de espécies das famílias Lauraceae, Fabaceae e Sapindaceae, muito comuns em áreas de Floresta Ombrófila Mista (mesmo alteradas), sendo assim um fator que contribuiu para que não fosse registrada uma maior similaridade entre as floras dos dois compartimentos e a de outros estudos.

Em ambas as unidades geopedológicas analisadas, constatou-se a presença de epifitismo composto de formas vasculares e avasculares. Bromélias dos gêneros Tillandsia e Achmea e a orquídea Oncidium varisolum (chuva-de-ouro) foram freqüentemente visualizadas colonizando troncos e galhos, juntamente com pteridófitas e briófitas. A presença de lianas e aráceas, como Phylodendrum sp., ocupando o estrato superior da floresta, também foi objeto freqüente de observação.

\section{Caracterização fitossociológica}

Informações fitossociológicas dos dois compartimentos estudados são apresentadas nas tabelas 3 e 4, onde as espécies se encontram relacionadas em ordem decrescente, de acordo com o valor de importância obtido.

A altura e o porte dos indivíduos amostrados determinaram um aspecto bem marcante na fisionomia da vegetação encontrada nos dois compartimentos. Para o Cambissolo Húmico, a altura média geral foi de 9,78 m, com Araucaria angustifolia atingindo alturas superiores a $20 \mathrm{~m}$ e PAP de até $346 \mathrm{~cm}$. Três estratos foram considerados para esse compartimento. O dossel apresentou árvores de copas densas e de maior porte, com a altura variando entre 18 e $25 \mathrm{~m}$. Araucaria angustifolia foi a espécie emergente e de maior destaque, tanto pela altura como pelo valor de importância (VI), tendo na dominância relativa (DoR) o parâmetro que mais influenciou para a geração de um alto VI da espécie. Abaixo dessa, indivíduos de Vernonia discolor, Capsicodendron dinisii, Myrceugenia oxysepala, Lithraea brasiliensis, Psychotria longipes, Podocarpus lambertii e Hovenia dulcis (espécie invasora) completaram o estrato superior (Figura 1).

No estrato intermediário ou subdossel (com árvores de altura média de 11,64 m), as principais espécies observadas foram Campomanesia xanthocarpa, Eugenia pluriflora, E. involucrata, Myrcia multiflora, Myrceugenia oxysepala, M. miersiana, Sapium glandulatum e Celtis iguanaea. Para o estrato inferior (com média de 6,13 m de altura), Casearia decandra, Jacaranda puberula, Duranta vestita, Calyptranthes concinna, Myrcia fallax, Xylopia brasiliensis e Solanum sanctae-catharinae constituíramse nas principais espécies verificadas.

Dentre as 35 espécies registradas para o Cambissolo Húmico, Podocarpus lambertii, Myrcia multiflora e Casearia sylvestris, Araucaria angustifolia, Lithraea brasiliensis, Capsicodendron dinisii e Myrceugenia oxysepala foram as que apresentaram a maior densidade relativa. Essas sete espécies contribuíram com cerca de $60 \%$ da densidade absoluta total.

Entre as de maior valor de importância (VI), sete apresentaram índice acima de 10,00, sendo essas, na seqüência, Araucaria angustifolia (50,94), Podocarpus lambertii (46,42), Myrcia multiflora (27,76), Lithraea brasiliensis (19,68), Capsicodendron dinisii $(15,54)$, Casearia sylvestris $(15,29)$ e Myrceugenia oxysepala $(13,84)$. Como espécies de maior dominância (incluindo indivíduos mortos não identificados), destacaram-se Podocarpus lambertii e Myrcia multiflora (14,68\%), Casearia sylvestris (7,70\%) e Araucaria angustifolia (6,99\%).

A área basal total encontrada para esse compartimento foi de 44,39 m²/ha, sendo Araucaria angustifolia, com 17,10 m²/ha, a espécie que apresentou a maior área, seguida de Podocarpus Lambertii $\left(9,75 \mathrm{~m}^{2} / \mathrm{ha}\right)$ e Lithraea brasiliensis $\left(2,92 \mathrm{~m}^{2} / \mathrm{ha}\right)$. A densidade estimada da comunidade foi de 1.430 indivíduos/ha, sendo Podocarpus lambertii, Myrcia multiflora e Casearia sylvestris as que mais contribuíram para se atingir esse valor.

$\mathrm{O}$ índice de diversidade Shannon $\left(\mathrm{H}^{\prime}\right)$ para as espécies encontradas em Cambissolo Húmico gerou um valor de 2,37 nats/ind. Esse resultado, de acordo com Nascimento et al. (2001), pode ser considerado de diversidade mediana, justificado, especialmente, pela compartimentação rigorosa usada e pelo fato de ser uma área em que houve intervenção antrópica. 


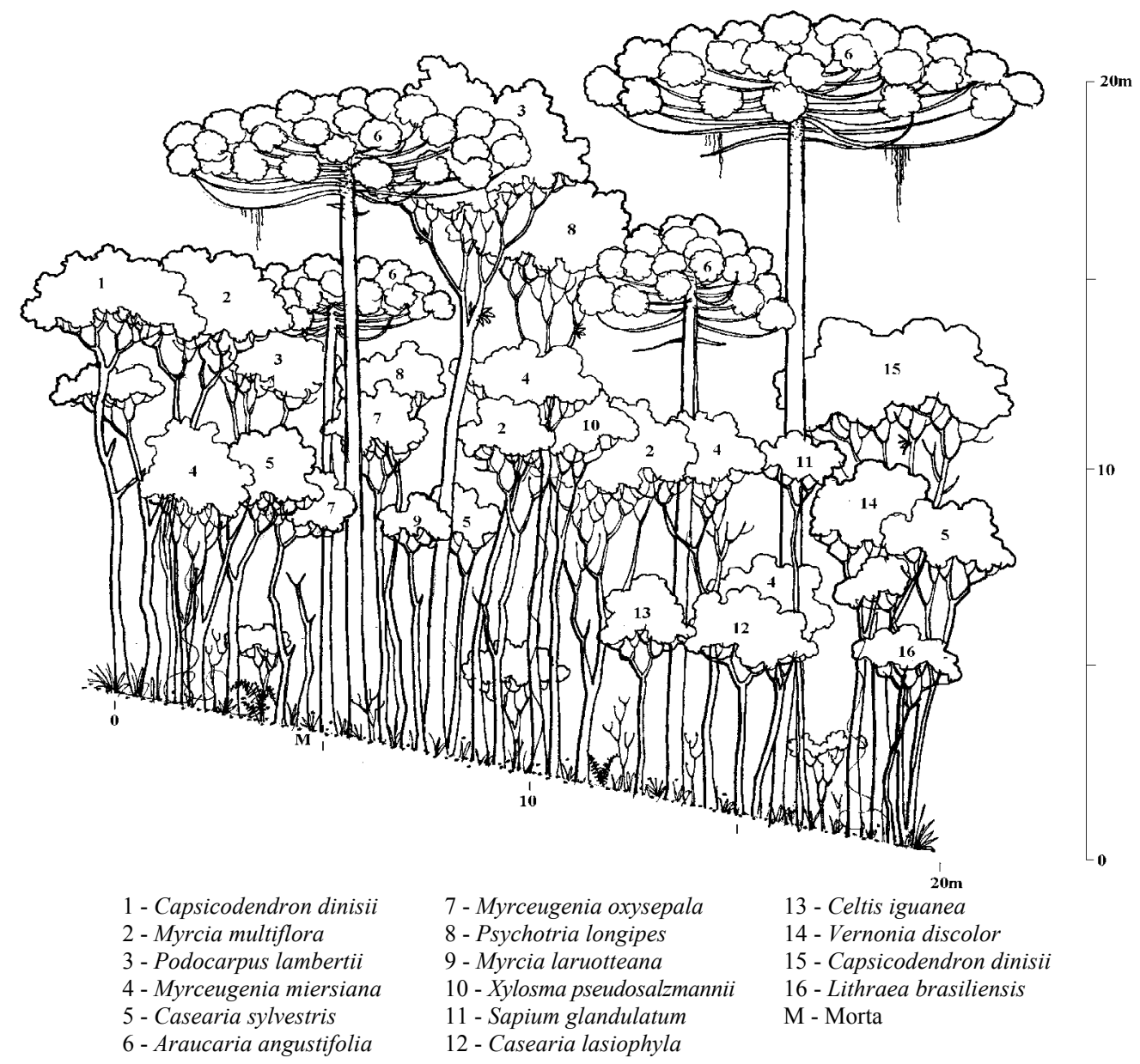

Figura 1. Perfil esquemático de um segmento da Floresta Ombrófila Mista Montana sobre Cambissolo Húmico.

Figure 1. Profile of a Montane Mixed Ombrophillous Forest on humic cambisoil.

O cálculo para a obtenção do índice de agregação de McGuinnes (IGA) demonstrou que nenhuma das espécies registradas em Cambissolo Húmico apresentou distribuição espacial que se caracteriza como de agregação. Já oito espécies, Araucaria angustifolia, Myrcia multiflora, Casearia sylvestris, Casearia decandra, Psychotria longipes, Calyptranthes concinna, Myrceugenia miersiana e Celtis iguanaea, apresentaram tendência ao agrupamento, enquanto que 11 tiveram ocorrência aleatória e as demais, distribuição uniforme.

Em Gleissolo Háplico, no qual a altura média encontrada foi em torno dos 7,23 m, teve Podocarpus lambertii, Myrcia multiflora, M. rostrata, Myrcengenia miersiana, Sebastiania commersoniana e $S$. brasiliensis foram dominantes e formadoras do dossel, vindo em seguida as demais a compor o subdossel imediatamente abaixo (Figura 2). Comparado ao Cambissolo Húmico, a altura e porte da maioria das árvores do presente compartimento foi em geral bem menor, com somente um indivíduo de Podocarpus lambertii atingindo altura estimada maior que $12 \mathrm{~m}$ e PAP de $124 \mathrm{~cm}$. Outra diferença marcante entre os dois compartimentos foi o número de indivíduos mortos: 23 (15,75\% dos indivíduos amostrados) ou 460 ind./ha para Gleissolo Háplico, contra 10 (6,54\%) ou 100 ind./ha para o Cambissolo Húmico, valor esse muito acima do esperado para ser enquadrado como normal (até $8 \%$ ). Alterações ambientais quando da implantação do condomínio, resultando em maior aporte de sedimentos e modificações no regime hídrico dos solos, são possíveis causas dessa mortalidade. 
A diferenciação existente entre a quantidade de indivíduos distribuídos nos diferentes estratos florestais nas duas unidades é representada na Figura 3.

Tabela 3. Relação de espécies amostradas para o compartimento Cambissolo Húmico e seus respectivos padrões sociológicos.

Table 3. List of sampled species from humic cambisoil and respective sociolgical patterns.

\begin{tabular}{|c|c|c|c|c|c|c|c|c|c|c|c|}
\hline Espécies & $\begin{array}{c}\mathrm{N}^{\mathbf{o}} \\
\text { Ind. }\end{array}$ & $\begin{array}{c}\text { H } \\
\text { Med. }\end{array}$ & $\begin{array}{l}\text { PAP } \\
\text { Max. }\end{array}$ & DA & DR & FA & FR & DoA & DoR & VI & IGA \\
\hline Araucaria angustifolia & 10 & 14,5 & 108,9 & 100 & 6,99 & 50 & 5,43 & 17,10 & 38,52 & 50,95 & 1,44 \\
\hline Podocarpus lambertii & 21 & 13,3 & 43,3 & 210 & 14,68 & 90 & 9,78 & 9,75 & 21,96 & 46,43 & 0,91 \\
\hline Myrcia multiflora & 21 & 8,5 & 18,8 & 210 & 14,68 & 80 & 8,69 & 1,95 & 4,39 & 27,77 & 1,31 \\
\hline Lithraea brasiliensis & 8 & 10,8 & 37,6 & 80 & 5,59 & 60 & 6,52 & 2,92 & 6,57 & 18,69 & 0,87 \\
\hline Capsicodendron dinisii & 8 & 10,8 & 33,4 & 80 & 5,59 & 50 & 5,43 & 2,01 & 4,52 & 15,56 & 0,28 \\
\hline Casearia sylvestris & 11 & 7,3 & 24,5 & 110 & 7,70 & 50 & 5,43 & 0,96 & 2,16 & 15,29 & 1,59 \\
\hline Myrceugenia oxysepala & 8 & 9,3 & 21,3 & 80 & 5,59 & 60 & 6,52 & 0,77 & 1,73 & 13,85 & 0,87 \\
\hline Myrceugenia miersiana & 5 & 8,4 & 22,0 & 50 & 3,49 & 30 & 3,27 & 0,74 & 1,66 & 8,42 & 1,40 \\
\hline Myrcia fallax & 5 & 7,4 & 7,0 & 50 & 3,49 & 40 & 4,34 & 0,14 & 0,31 & 8,16 & 0,98 \\
\hline Celtis iguanea & 5 & 8,4 & 16,6 & 50 & 3,49 & 30 & 3,27 & 0,47 & 1,05 & 7,82 & 1,40 \\
\hline Vernonia discolor & 3 & 12,3 & 22,3 & 30 & 2,09 & 30 & 3,27 & 1,00 & 2,25 & 7,61 & 0,85 \\
\hline Myrcia laruotteana & 1 & 2,0 & 49,7 & 10 & 0,70 & 10 & 1,08 & 1,94 & 4,37 & 6,16 & 1,00 \\
\hline Eugenia uruguayensis & 2 & 12,5 & 32,8 & 20 & 1,39 & 20 & 2,17 & 0,95 & 2,14 & 5,71 & 0,90 \\
\hline Sapium glandulatum & 3 & 8,3 & 10,2 & 30 & 2,09 & 30 & 3,27 & 0,17 & 0,38 & 5,74 & 0,85 \\
\hline Casearia decandra & 3 & 7,7 & 10,2 & 30 & 2,09 & 20 & 2,17 & 0,17 & 0,38 & 4,65 & 1,36 \\
\hline Hovenia dulcis & 2 & 14,5 & 15,6 & 20 & 1,39 & 20 & 2,17 & 0,38 & 0,85 & 4,43 & 0,90 \\
\hline Eugenia pluriflora & 2 & 9,5 & 14,3 & 20 & 1,39 & 20 & 2,17 & 0,23 & 0,51 & 4,09 & 0,90 \\
\hline Campomanesia xanthocarpa & 2 & 13,0 & 14,6 & 20 & 1,39 & 20 & 2,17 & 0,22 & 0,49 & 4,07 & 0,90 \\
\hline Casearia lasiophyla & 2 & 7,0 & 10,5 & 20 & 1,39 & 20 & 2,17 & 0,11 & 0,24 & 3,82 & 0,90 \\
\hline Psychotria longipes & 2 & 13,5 & 25,8 & 20 & 1,39 & 10 & 1,09 & 0,64 & 1,44 & 3,93 & 2,00 \\
\hline Xylosma pseudosalzmannii & 2 & 9,0 & 13,1 & 20 & 1,39 & 20 & 2,17 & 0,16 & 0,36 & 3,93 & 0,90 \\
\hline Symplocos tetrandra & 2 & 9,0 & 10,5 & 20 & 1,39 & 20 & 2,17 & 0,15 & 0,34 & 3,91 & 0,90 \\
\hline Duranta vestita & 2 & 7,5 & 11,8 & 20 & 1,39 & 20 & 2,17 & 0,14 & 0,31 & 3,89 & 0,90 \\
\hline Sorocea bomplandii & 1 & 11,0 & 19,1 & 10 & 0,70 & 10 & 1,09 & 0,29 & 0,65 & 2,44 & 1,00 \\
\hline Calyptranthes concinna & 2 & 5,5 & 5,4 & 20 & 1,39 & 10 & 1,09 & 0,04 & 0,09 & 2,58 & 2,00 \\
\hline Eugenia involucrate & 1 & 12,0 & 15,9 & 10 & 0,70 & 10 & 1,09 & 0,20 & 0,45 & 2,24 & 1,00 \\
\hline Myrsine parvula & 1 & 11,0 & 15,3 & 10 & 0,70 & 10 & 1,09 & 0,18 & 0,40 & 2,19 & 1,00 \\
\hline Myrcia hatschbachii & 1 & 11,0 & 13,4 & 10 & 0,70 & 10 & 1,09 & 0,14 & 0,31 & 2,10 & 1,00 \\
\hline Jacaranda puberula & 1 & 7,0 & 12,7 & 10 & 070 & 10 & 1,09 & 0,13 & 0,28 & 2,08 & 1,00 \\
\hline Myrceugenia sp. & 1 & 12,4 & 12,4 & 10 & 0,70 & 10 & 1,09 & 0,12 & 0,27 & 2,06 & 1,00 \\
\hline Guatteria australis & 1 & 8,0 & 9,2 & 10 & 0,70 & 10 & 1,09 & 0,07 & 0,15 & 1,94 & 1,00 \\
\hline Sloanea sp. & 1 & 7,0 & 7,6 & 10 & 0,70 & 10 & 1,09 & 0,05 & 0,10 & 1,90 & 1,00 \\
\hline Xylopia brasiliensis & 1 & 6,0 & 7,0 & 10 & 0,70 & 10 & 1,09 & 0,04 & 0,09 & 1,88 & 1,00 \\
\hline Solanum sanctae-catharinae & 1 & 3,0 & 6,7 & 10 & 0,70 & 10 & 1,09 & 0,04 & 0,08 & 1,88 & 1,00 \\
\hline$\underline{\text { Sebastiania brasiliensis }}$ & 1 & 3,0 & 4,8 & 10 & 0,70 & 10 & 1,09 & 0,02 & 0,04 & 1,83 & 1,00 \\
\hline Totais & 143 & & & 1430 & $\mathbf{1 0 0 , 0 0}$ & 920 & $\mathbf{1 0 0 , 0 0}$ & 44,39 & 100,00 & $\mathbf{3 0 0 , 0 0}$ & \\
\hline Mortas & 10 & 1,0 & 15,6 & 100 & 6,54 & 70 & 7,07 & 0,80 & 1,78 & 15,39 & 0,83 \\
\hline
\end{tabular}

Dentre as espécies registradas, Myrsine umbellata (32,24\%), Podocarpus lambertii (20,48\%), Sebastiania commersoniana (8,99\%), Lithraea brasiliensis (6,54\%) e Myrcia palustris (5,14\%) foram as de maior dominância relativa, contribuindo com aproximadamente $52 \%$ da densidade absoluta total encontrada nesse compartimento.

O valor de importância (VI) apontou Myrsine umbellata $(63,05)$, Sebastiania commersoniana $(38,59)$, Podocarpus lambertii $(27,49)$, Sebastiania brasiliensis $(15,96)$ e Schinus terebinthifolius $(14,20)$ como as cinco espécies mais representativas, constituindo-se nas espécies com maior número de indivíduos por hectare.

O índice de diversidade Shannon ( $\mathrm{H}^{\top}$ ) foi de 2,18 nats/ind. A área basal total foi de $26,61 \mathrm{~m}^{2} / \mathrm{ha}$, sendo Myrsine umbellata $\left(8,58 \mathrm{~m}^{2} / \mathrm{ha}\right)$ e Podocarpus lambertii $\left(5,45 \mathrm{~m}^{2} / \mathrm{ha}\right)$ as de maior destaque nesse parâmetro. A densidade da comunidade florística em Gleissolo Háplico atingiu um valor de 2.460 indivíduos/ha, valor bem maior do que o encontrado para o Cambissolo Húmico. 


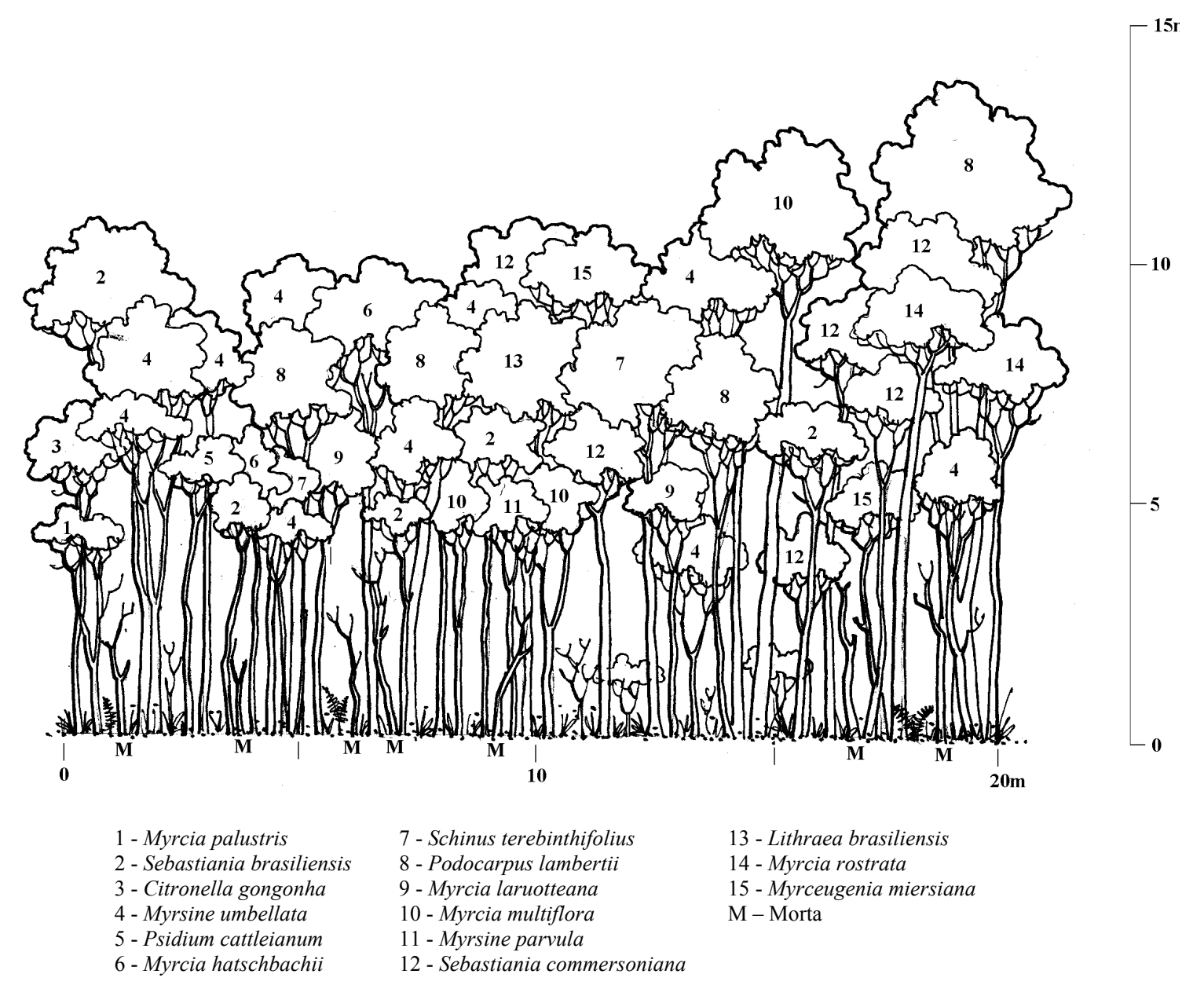

Figura 2. Perfil esquemático de um segmento da Floresta Ombrófila Mista Montana sobre Gleissolo Húmico. Figure 2. Profile of the Aluvial Mixed Ombrophillous Forest on gleisoil.

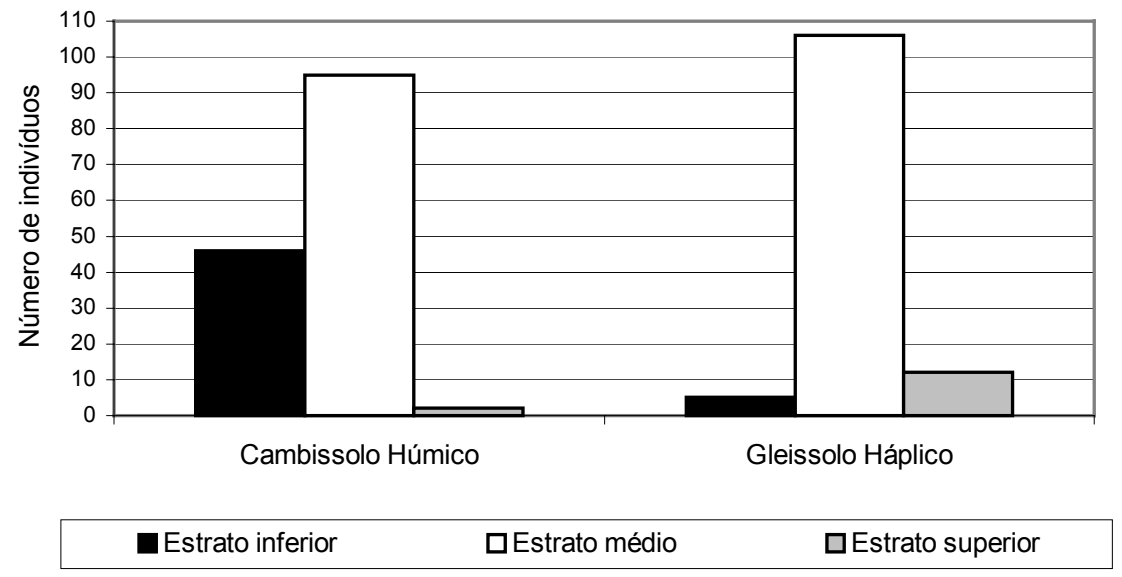

Figura 3. Número de indivíduos por estrato nos dois compartimentos estudados.

Figure 3. Number of individuals in forest layer at the two geo-pedological unitis sampled.

FLORESTA, Curitiba, PR, v. 35, n. 2, mai./ago. 2005. 
Tabela 4. Relação de espécies amostradas para o compartimento Gleissolo Háplico e seus respectivos padrões sociológicos.

Table 4. List o f species sampled from gleisoil and respective sociolgical standart.

\begin{tabular}{|c|c|c|c|c|c|c|c|c|c|c|c|}
\hline Espécies & $\begin{array}{c}\mathbf{N}^{\mathbf{o}} \\
\text { Ind. }\end{array}$ & $\begin{array}{c}\mathbf{H} \\
\text { Med. }\end{array}$ & $\begin{array}{l}\text { PAP } \\
\text { Max. }\end{array}$ & DA & DR & FA & FR & DoA & DoR & VI & IGA \\
\hline Myrsine umbellata & 36 & 7,4 & 29,3 & 720 & 29,27 & 100 & 10,0 & 8,58 & 32,24 & 71,51 & 7,20 \\
\hline Sebastiania commersoniana & 18 & 8,0 & 19,4 & 360 & 14,64 & 80 & 8,0 & 2,63 & 9,88 & 32,52 & 2,25 \\
\hline Podocarpus lambertii & 5 & 10,0 & 39,5 & 100 & 4,07 & 60 & 6,0 & 5,45 & 20,48 & 30,55 & 1,09 \\
\hline Sebastiania brasiliensis & 9 & 6,1 & 9,5 & 180 & 7,31 & 80 & 8,0 & 0,74 & 2,79 & 18,10 & 1,12 \\
\hline Schinus terebinthifolius & 7 & 7,1 & 17,8 & 140 & 5,69 & 60 & 6,0 & 1,16 & 4,35 & 16,04 & 1,53 \\
\hline Myrcia multiflora & 6 & 8,7 & 12,7 & 120 & 4,87 & 60 & 6,0 & 0,83 & 3,12 & 13,97 & 1,31 \\
\hline Myrcia hatschbachii & 6 & 7,3 & 11,1 & 120 & 4,87 & 60 & 6,0 & 0,53 & 1,99 & 12,86 & 1,31 \\
\hline Lithraea brasiliensis & 2 & 8,5 & 25,8 & 40 & 1,62 & 40 & 4,0 & 1,74 & 6,54 & 12,16 & 0,80 \\
\hline Myrcia palustris & 3 & 6,7 & 28,6 & 60 & 2,43 & 40 & 4,0 & 1,37 & 5,14 & 11,57 & 1,17 \\
\hline Myrcia laruotteana & 4 & 6,8 & 7,0 & 80 & 3,25 & 60 & 6,0 & 0,26 & 0,98 & 10,23 & 0,87 \\
\hline Myrcia rostrata & 5 & 8,0 & 9,9 & 100 & 4,07 & 40 & 4,0 & 0,52 & 1,95 & 10,02 & 0,49 \\
\hline Myrcia fallax & 2 & 10,0 & 19,1 & 40 & 1,62 & 40 & 4,0 & 0,65 & 2,44 & 8,06 & 0,78 \\
\hline Myrceugenia miersiana & 3 & 8,7 & 11,1 & 60 & 2,44 & 40 & 4,0 & 0,33 & 1,25 & 7,69 & 0,80 \\
\hline Myrsine parvula & 3 & 5,5 & 7,6 & 60 & 2,44 & 40 & 4,0 & 0,23 & 0,86 & 7,30 & 0,80 \\
\hline Citronela gongonha & 2 & 7,0 & 10,8 & 40 & 1,62 & 40 & 4,0 & 0,35 & 1,32 & 6,94 & 0,78 \\
\hline Calyptranthes concinna & 4 & 9,5 & 10,5 & 80 & 3,25 & 20 & 2,0 & 0,41 & 1,54 & 6,79 & 3,63 \\
\hline Psidium cattleyanum & 2 & 6,0 & 8,0 & 40 & 1,63 & 40 & 4,0 & 0,15 & 0,56 & 6,19 & 0,78 \\
\hline Sapium glandulatum & 2 & 4,5 & 13,4 & 40 & 1,63 & 20 & 2,0 & 0,33 & 1,25 & 4,88 & 1,81 \\
\hline Psychotria longipes & 1 & 10,0 & 10,8 & 20 & 0,82 & 20 & 2,0 & 0,18 & 0,67 & 3,49 & 0,90 \\
\hline Blepharocalyx salicifolius & 1 & 6,0 & 6,7 & 20 & 0,82 & 20 & 2,0 & 0,07 & 0,26 & 3,08 & 0,90 \\
\hline Ilex theezans & 1 & 7,0 & 6,4 & 20 & 0,82 & 20 & 2,0 & 0,06 & 0,23 & 3,05 & 0,90 \\
\hline Myrceugenia sp. & 1 & 6,0 & 5,1 & 20 & 0,82 & 20 & 2,0 & 0,04 & 0,16 & 2,98 & 0,90 \\
\hline Totais & 123 & & & 2460 & 100,00 & 1000 & $\mathbf{1 0 0 , 0 0}$ & 26,61 & $\mathbf{1 0 0 , 0 0}$ & $\mathbf{3 0 0 , 0 0}$ & \\
\hline Mortas & 23 & 5,1 & 8,2 & 460 & 15,75 & 100 & 9,09 & 2,65 & 9,06 & 33,90 & 4,60 \\
\hline
\end{tabular}

Quanto ao aspecto de agregação (IGA), três espécies - Myrsine umbellata, Sebastiania commersoniana e Calyptranthes concinna - apresentaram agregação de indivíduos. Outras sete, Podocarpus lambertii, Sebastiania brasiliensis, Schinus terebinthifolius, Myrcia multiflora, M. hatschbachii, M. palustris e Sapium glandulatum, apresentaram tendência ao agrupamento, enquanto que as restantes apresentaram distribuição uniforme.

\section{CONCLUSÕES}

A área de estudo é considerada como um importante remanescente de Floresta Ombrófila Mista, devido à situação crítica em relação à sua conservação. A estrutura e a fisionomia aparente da vegetação foram consideradas como indícios de que interferências antrópicas ocorreram na área em anos passados, no entanto, ainda apresenta características da composição florística original devido à presença de indivíduos de grande porte, como é o caso de Araucaria angustifolia (pinheiro-do-paraná).

A quantidade de espécies registradas está na média do que geralmente se encontra em capões de floresta com araucária alterada. Quanto às famílias, a maior quantidade de espécies da família Myrtaceae e Flacourtiaceae também segue um padrão. No entanto, a não-presença de espécies de famílias típicas, como Fabaceae, Sapindaceae e Lauraceae, fugiu à regra e poderia estar relacionada à ocorrência de uma intensa exploração seletiva ou ao atual estágio sucessional do remanescente estudado.

Da comparação entre os compartimentos geopedológicos estudados (Cambissolo Húmico e Gleissolo Háplico), resultou uma baixa similaridade florística entre ambos, evidenciando também diferenças entre o porte e quantidade de indivíduos nos dois compartimentos. Enquanto que para o Cambissolo Húmico as árvores apresentavam maior tamanho (área basal maior) com menor número de indivíduos por unidade de área, para o Gleissolo Háplico eram mais finas e em maior número. Outra característica diferencial constatada está relacionada ao aspecto de agregação. No caso do Cambissolo Húmico, a maioria das espécies apresentou distribuição espacial uniforme ou aleatória, com nenhum caso de agregação, distintamente do Gleissolo Háplico, onde três espécies apresentaram comportamento de agregação, com destaque para Myrsine umbellata. Surpreenderam os valores obtidos de indivíduos mortos em Gleissolo Háplico - 15,75\% dos indivíduos amostrados, contra 6,54\% para o Cambissolo 
Húmico. Alterações ambientais em áreas adjacentes a montante, especialmente quando da implantação do condomínio, proporcionaram fases de soterramento bastante espessas que poderiam ser parte das possíveis causas dessa mortalidade.

\section{AGRADECIMENTOS}

Os autores agradecem à administração do Condomínio Residencial Alphaville Graciosa, pela oportunidade de desenvolver o presente estudo em uma de suas áreas de preservação. Agradecem também ao pesquisador Gustavo Ribas Curcio, da Embrapa Floresta, pelo mapeamento e descrição dos solos, e aos botânicos Gerdt Hatschbach, do Museu Botânico de Curitiba, e Marcos Sobral, da Universidade Federal de Minas Gerais, pelo auxílio na identificação de determinadas espécies.

\section{REFERÊNCIAS}

AMBIENTE BRASIL. Projeto pinhão. "Floresta Ombrófila Mista". Disponível em http://pinho.floresta.ufpr.br/ pinhao/floresta.htm. Acesso: 28 mar. 2004.

EMBRAPA. Sistema brasileiro de classificação de solos. Rio de Janeiro, 1999. 412p.

FIDALGO, O.; BONONI, V. L. R. (Cords.). Técnicas de coleta, preservação e herborização de material botânico. São Paulo: Instituto de Botânica, 1984. (Manual, 4).

FUNDAÇÃO DA UNIVERSIDADE FEDERAL DO PARANÁ PARA O DESENVOLVIMENTO DA CIÊNCIA, DA TECNOLOGIA E DA CULTURA. Relatório Final - Diagnóstico e Monitoramento da Cobertura Vegetal da área de Influência Direta e Indireta do Vazamento de Óleo da Refinaria Presidente Getúlio Vargas - REPAR, Araucária/PR, Fase II - Diagnóstico, Curitiba/PR, Jan/2002, 63p.

FUPEF; CNPq “Conservação do Bioma Floresta com Araucária”: Relatório Final. Curitiba, 2001.

IBGE. Departamento de Recursos Naturais e Estudos Ambientais, Manual técnico da vegetação brasileira. (Série manuais técnicos em geociências, n.1), Rio de Janeiro, 1992.

LEITE, P. F. As diferentes unidades Fitoecológicas da Região Sul do Brasil proposta de Classificação, Curitiba, 1994. 160f. Dissertação (Mestrado em Engenharia Florestal) Setor de Ciências Agrárias, Universidade Federal do Paraná.

MAACK, R. Geografia do Paraná. Rio de Janeiro: José Olympio, 1981.

MAGURRAN, A E. Diversidad ecológica y su medición. Barcelona: Vedrá, 200p. 1989

MUELLER-DOMBOIS, D.; ELLEMBERG, H. Aims ans methods of vegetation ecology. New York: Wiley \& Sons, 1974. 547p.

NASCIMENTO, A., R., T.; LONGHI, S. J.; BRENA, A. D. Estrutura e padrões de distribuição espacial de espécies arbóreas em uma amostra de Floresta Ombrófila Mista em Nova Prata, RS. Ciência Florestal, Santa Maria, v.11, n.1, p.105-119, 2001.

NEGRELLE, R. A. B.; SILVA, F. C. Fitossociologia de um trecho de Floresta com Araucária Angustifolia (Bert.) O. Ktze. No Município de Caçador - SC. Boletim Pesquisa Florestal, Colombo PR, n.25/25, p.37-54. 1992.

RESITEC. Estudo de Impacto Ambiental (EIA) do Loteamento Residencial Alphaville Graciosa. Pinhais, 1999.

RONDON NETO, R. M.; KOZERA, C.; ANDRADE, R. R.; CECY, A. T.; HUMMES, A. P.; FRITZONS, E.; CALDEIRA, M. V. W.; MACIEL, M. N. M.; SOUZA, M. K. F. Caracterização florística e estrutural de um fragmento de Floresta Ombrófila Mista, em Curitiba, PR - Brasil. Floresta, Curitiba, v.32, n.1, p.3-16. 2002 . 
SANQUETA, C. R.; PIZATTO, W.; PÉLliCO NETO, S.; FIGUEIREDO FILHO, A. ; EISFELD, R. L. Estrutura vertical de um fragmento de Floresta Ombrófila Mista no Centro-Sul do Paraná. Floresta, v.32, n.2, Curitiba, p.267-276, 2002.

SHEPHERD, G. J. Fitopac - versão preliminar: manual do usuário. Campinas: 1988. Universidade Estadual de Campinas. 